\title{
FICÇÃO DE GÊNERO: ENTRE A NOVA EVA DE ANGELA CARTER E O CIBORGUE DE DONNA HARAWAY
}

RESUMO:

Em The Passion of New Eve, Angela Carter prefigura a fabricação de um ser humano por força de tecnologias materiais $e$ discursivas. Este ser, chamado Eva, mantém sua antiga identidade masculina em conflito com sua nova condição como mulher. Segundo a teoria de Haraway, esse hibridismo torna Eva um ciborgue, metáfora para a atual condição humana.

PALAVRAS-CHAVE: estudos de gênero, a ciência e a ficção.

"our flesh arrives to us out of history, like everything else" Angela Carter

Recentemente algumas intelectuais do campo das chamadas Ciências Naturais têm destacado-se por desenvolver pesquisas em torno dos Estudos de Gênero. Esta, que é claramente uma abordagem interdisciplinar, tem se mostrado bastante produtiva, uma vez que dá a luz um olhar politizado sobre os estudos de gênero, seja dentro da ciência, seja na cultura, e, melhor ainda, acaba por entrecruzá-los. Como resultado, esse tipo de abordagem permite problematizar o lugar ocupado pelo gênero na cultura e o que a ciência nos diz sobre isso.

Focalizando igualmente questões desse tripé, ou seja, gênero, natureza (ciência) e cultura, o romance The Passion of New Eve, ou A Paixão da Nova Eva, 1977, da escritora inglesa Ângela Carter, vem possibilitar um interessante paralelo entre as concepções científicas e culturais acerca do gênero, notadamente no pensamento ocidental. Em vista disso, neste trabalho eu pretendo apontar e debater algumas questões levantadas principalmente pela bióloga Donna Haraway, que tem desenvolvido * Mestre em Letras: Estudos Literários (Área de concentração: Literaturas de Expressão Inglesa), 2000. 


\section{EM TESE}

Belo Horizonte, v. 5, p. I-305, dez. 2002

um trabalho inovador sobre o gênero no campo científico, e discutir de que forma 0 romance de Carter prefigurou idéias que só contemporaneamente ganharam espaço.

The Passion of New Eve apresenta-se como uma ousada paródia do Gênesis, mito da criação predominante no 0cidente, e acaba por apropriar-se, ainda, de uma série de outras figuras mitológicas para compor a narrativa. Inegavelmente pósmoderno, o texto de Carter vale-se do que é mais representativo da tradição para aplicar ao gênero uma nova roupagem a partir dos destroços dessa mesma tradição.

Remontando peripécias comuns em contos de fadas ou na trajetória de figuras mitológicas, o protagonista de Carter, Evelyn, é um medíocre professor inglês em viagem aos E.U.A. Incorporando um comportamento altamente misógino, Evelyn é um herói às avessas. Estereótipo de um típico 'macho man', vil e egoísta, Evelyn é seqüestrado por uma comunidade de mulheres guerreiras, como as legendárias Amazonas, sequiosas por vingança contra os males do patriarcado e lideradas pela Grande Mãe, uma deusa ctônica em carne e osso.

Nesse ponto começa o destronamento de Evelyn e, portanto, dos valores patriarcais que ele representava até então, bem como tem início a des-construção do mito bíblico. A Grande Mãe, oposta à figura do deus cristão, masculino e celeste, é a divindade feminina e ctônica que transforma Evelyn em Eve (Eva), promovendo sua castração, metaforizada pelo corte em seu nome, e transformação em uma mulher, através de uma cirurgia plástica e de um ciclo de psico-programação.

Literalmente transformada em uma mulher, não a partir da costela de um homem, mas a partir de todo o seu corpo, Eva mostra-se uma pessoa dividida entre seu novo corpo e as memórias de seu antigo corpo. Nem homem, nem mulher, mas inegavelmente uma fêmea com todas as funções peculiares, principalmente as reprodutivas, Eva iria ser usada pela Grande Mãe como a matriz a partir da qual uma nova cosmogonia, centrada na mulher, seria instaurada em resposta aos terrores do patriarcado.

Ironicamente, apesar de opor-se ao patriarcado, nota-se que a matriarca Grande Mãe pretendia infligir a Eva o mesmo tipo de violência simbólica por que a mulher normalmente passa até efetivamente "tornar-se mulher", na acepção de Beauvoir, quem, já em 1949, alertou que o papel social vivido pela mulher é antes uma imposição da sociedade do que o resultado de um instinto natural qualquer (beauvoir 
1953: 249). No lugar de vivenciar as chamadas "tecnologias do gênero", i.e., as estratégias discursivas através das quais a cultura promove e reforça determinados valores a serem assimilados, Eva passaria por um processo artificial de psicoprogramação que consistia em injeções de hormônios, exposição massiva a vídeos sobre maternidade, lições sobre feminilidade, representações artísticas do feminino na literatura, pintura, cinema, etc. Tais mecanismos, como explica Teresa de Lauretis, em seu trabalho critico Technologies of Gender, 1987, constituem as diversas formas de representação de gênero e, como tais, contribuem para engendrar no meio social relações de gênero hierarquizadas (3-5).

Eva, que tinha sido também um intelectual, reconheceu a tempo as estratégias para a sua psico-programação. Temendo ter seu corpo apropriado como instrumento para concretizar o plano revolucionário da Grande Mãe, Eva foge do laboratório da Grande Mãe, onde deveria assimilar uma identidade feminina e essencialmente materna, evocada pelo próprio nome 'Eva', destinada a popular um novo mundo matriarcal.

Nesse contexto, metaforizado por um laboratório onde se ensaia a construção artificial de uma identidade, a ficção de Carter comunica-se com a teoria de Donna Haraway. Carter, em um laboratório ficcional, e Haraway, em seu laboratório científico, chegam à mesma constatação de que identidades podem ser forjadas e, portanto, manipuladas, a fim de atender interesses alheios, quer dizer, com os quais o indivíduo não se identifica a priori. Este indivíduo, após se expor ou ser exposto, às diversas representações difusas no meio, ou seja, cadeias de signos, como cinema, discursos institucionalizados, epistemologias, crítica e notadamente práticas da vida cotidiana (1auretis 1987:2), passa, então, a estabelecer relações de semelhança, pertencimento ("kinship") e orientar-se pelo que entende como idêntico em contraponto à diferença. Daí, segundo lembra Lauretis (1987:5) e Haraway (1997:126), é que se formam as diversas facções que subdividem as sociedades entre si e dentro de si mesmas, pelos diversos grupos internos, como classe, gênero, etnia, religião, sexualidade, entre outros.

Em vista das influências internas, ditas genéticas, e externas, ditas sociais, que influenciam na identidade adquirida pelo indivíduo, Haraway pontua que nós, como sujeitos moldados a partir de uma herança genética e cultural, somos na verdade ciborgues, meio máquinas, meio humanos, meio textos (1991:150). Vale dizer que, 


\section{EMTESE}

Belo Horizonte, v. 5, p. I-305, dez. 2002

enquanto máquinas e textos, somos duplamente híbridos, ao mesmo tempo corpos orgânicos, consumidores de alta tecnologia em grande escala e receptores de signos disseminados na cultura. Haraway lembra-nos que, nestas condições de vida, a um tempo orgânica, sintética e textual, o sujeito coloca-se em dominios fronteiriços, entre tensões limítrofes de áreas de poder. Nessas condições o ciborgue, convivendo cotidianamente com elementos contraditórios, abre vista para uma nova maneira de lidar com as diferenças.

Por esta natureza híbrida, orgânica e sintética, corpo e cultura, o ciborgue de Haraway equipara-se ao protótipo chamado 'Eva' no texto de Carter. Ambos ficção, engendrados por tecnologias materiais e discursivas, Eva e o ciborgue vingam problematizar o conceito de "humanidade" e, principalmente, de diferença e igualdade, que têm demonstrado o modo pouco crítico com que temos nos avaliado. No contemporâneo Modest-WitnesseSecond_Millennium, título que já atenta para nossa nova realidade tecnológica, Haraway insere a ilustração de um ciborgue, representativo de nossa atual condição:

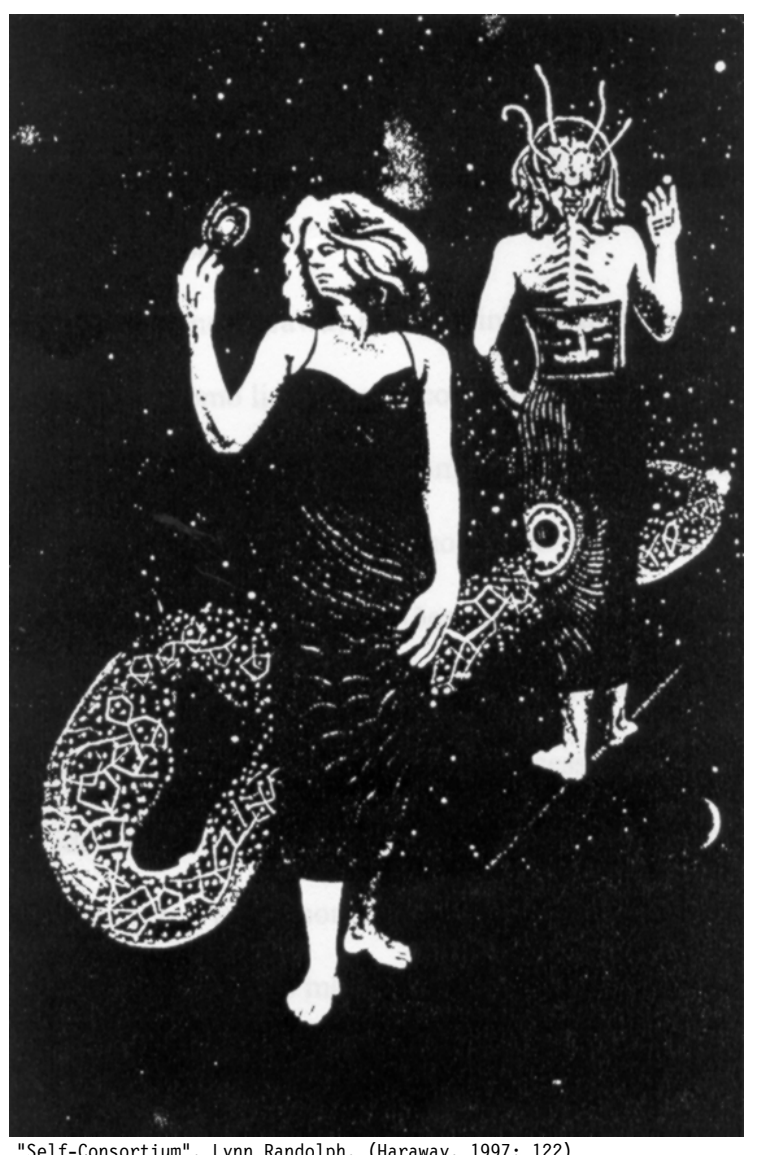

"Self-Consortium". Lynn Randolph. (Haraway, 1997: 122) 
Repare-se que, ao olhar para a palma de sua própria mão, o ciborgue encena uma relação especular, propiciando um olhar sobre si mesmo, através do qual contempla sua natureza híbrida, ou seja, o Outro diferente que também o constitui. Vale notar que não há sinais de horror, estranhamento ou tristeza na expressão desse ciborgue, o que indica não só o reconhecimento de suas diferenças, mas também a possibilidade de sua aceitação. Já a escolha do gênero feminino para esse ciborgue é um contraponto, intencional e oportuno, ao elemento masculino como símbolo representativo universal da humanidade e também uma curiosa maneira de olhar a espécie humana sincronicamente, para dentro de si mesma, em oposição à famosa ilustração da teoria da evolução humana, em que se retrata a progressão da espécie do macaco ao Homo sapiens. 0 ciborgue é a nova fronteira.

A crítica de teoristas como Haraway abre caminhos para um ol har diferente sobre nossa humanidade, alerta-nos sobre como lidamos mal com diferenças em geral, além de apontar abordagens alternativas para o que entendemos como diferente. De outro lado, já discutida anteriormente, a 'Nova Eva', de Carter, antecipa no campo literário uma ficção, até certo ponto científica, através da qual Carter joga com questões sobre identidade e gênero de uma forma que só recentemente encontra eco em teorias como a de Haraway. Ao retratar, em The Passion of New Eve, que o gênero é uma categoria cunhada num processo de aculturação e socialização, Carter aponta para a idéia do gênero como ficção inventada na emaranhada teia do discurso, qualquer que seja sua natureza. Assim, como preconiza Carter e como argumenta Haraway, resta a constatação de que somente lançando mão do poder que temos sobre o discurso, ou seja, escolhendo os enredos de nossas próprias estórias, é possível passarmos de atores para autores, senão ambos, da inescapável ficção em que vivemos.

ABSTRACT :

Carter's The Passion of New Eve envisages the fabrication of a human being by force of material and discursive technologies. Consequently, this being, named Eve, keeps her past identity, as man, in conflict with her new condition as woman. Based on Haraway's theory, this hybridism turns Eve into a cyborg, symbolizing the present condition of humankind.

KEY WORDS: gender studies, science and fiction. 
ANGIER, Natalie. Woman: an intimate geography. New York: Peter Davison Book, 1999.

BAUER, Dale M.; Mckinstry, Susan J. (Ed.). Feminism, Bakhtin and the dialogic. New York: State University Press, 1991.

BAKHTIN, Mikhail. Rabelais and his world. Trad. Hélène Iswolsky. Bloomington: Indiana UP, 1984.

BEAUVOIR, Simone de. The second sex. New York: Bantam Books, 1953.

BUTLER, Judith. Feminism and the subversion of identity. New York: Routledge, 1990.

CARTER, Angela. The passion of new Eve. London: Virago, 1982.

D'EAUBOONE, Françoise. As mulheres antes do patriarcado. Trad. Manuel Campos e Alexandra Freitas. Lisboa: Editorial Veja, 1977.

FOUCAULT, Michel. The history of sexuality: an introduction. V.I, New York: Vintage Books, 1997.

HARAWAY, Donna J. Simians, cyborgs, and women: the reinvention of nature. New York: Routledge, 1991.

HARAWAY, Donna J. Modest_WitnessoSecond_Millennium. FemaleMan৫ Meets OncoMouse ${ }^{\mathrm{m}}$ : feminism and téchnoscience. New York: Routlēedge, 1997.

HUTCHEON, Linda. A Poetics of postmodern: history, theory, fiction. New York: Routledge, 1991.

LAURETIS, Teresa de. Technologies of gender: essays on theory, film, and fiction. Bloomington: Indiana University Press, 1987.

MEANEY, Gerardine. (Un)Like subjects: women, theory, fiction. London: Routledge, 1993.

Mielietinski, E. M. A Poética do mito. Trad. Paulo Bezerra. Rio de Janeiro: Forense-Universitária, 1987.

MOI, Tori1. Sexual/Textual Politics: Feminist Literary Theory. London: Routledge, 1985.

SAGE, Lorna (Ed.). Flesh and the mirror: essays on the art of Angela Carter. London: Virago, 1994.

STALLYBRASS, Peter and Allon White. The politics \& poetics of transgression. Ithaca: Cornell University Press, 1986.

WOOLF, Virginia. A room of one's own. New York: HBJ, 1992. 